\title{
A geriatric study of longevity via big data analytics of metabolism and medical conditions using $\mathrm{GH}$ - Method: math-physical Medicine (No. 284)
}

\section{Introduction}

This paper describes the author's theory and daily practice of preventive medicine via big data analytics based on a quantitative and precision medicine approach. Undeniably, diet, exercise and details of medical conditions are important to longevity; however, he decided to address the overall root causes of various chronic diseases, with a special emphasis on two vital factors, stress and daily life routine regularity which have been greatly ignored. In this particular article, he includes his macro-view relationship between life longevity and overall metabolic status.

\section{Methods}

The author spent $\sim 30,000$ hours over the past 10 years, from 2010 to 2020 , to conduct his research on chronic diseases and complications, along with endocrinology, specifically focusing on metabolism and glucose.

In the beginning, from 2010 to 2013 , he self-studied internal medicine and food nutrition. He specifically focused on six chronic diseases, i.e. obesity, diabetes, hypertension, hyperlipidemia, cardiovascular diseases (CVD) \& stroke, and chronic kidney disease (CKD). In 2014, he allotted the entire year to develop a complex mathematical metabolism model which includes 4 output categories (weight, glucose, blood pressure, lipids) and 6 input categories (food, water, exercise, sleep, stress, life routine regularity). There are about 500 detailed elements included in these 10 categories. Since using a theoretical approach to deal with a dataset of 10 categories with 500 elements, the problem of identifying and solving all possible interactive relationships among them would be an immense task. This task would include complicated calculations of 500 ! steps. This kind of approach is a huge undertaking without any obvious benefit; therefore, he adopted an approach of applying mathematical concept that is topology. In addition, he applied a practical engineering modeling technique such as finite element method to seek a quicker but rather accurate solution for this complicated biomedical system. At the end, he was able to develop a mathematical metabolism model embedded in a specially designed application software on the iPhone ("eclaireMD system") for his daily use in order to maintain his health status and also serve as a useful research tool for his ongoing various medical research projects. During the development process, he has defined two more new variables, metabolism index (MI) and general health status unit (GHSU), where GHSU is the 90-days moving average MI that is similar to HbA1C's 90-days moving average glucoses. The results of this dynamic model can be expressed through these two newly defined variables, MI and GHSU, to describe a person's overall health status and shortcomings in any specific area at any moment in time.

In lifestyle management domain, food, water intake, exercise, sleep, stress, and daily life routines directly affect the medical conditions associated with chronic diseases.
Volume 5 Issue 5 - 2020

\author{
Gerald C Hsu \\ Medical Research Scientist, eclaireMD Foundation, USA
}

Correspondence: Gerald C Hsu, Medical Research Scientist, eclaireMD Foundation, USA, Email g.hsu@eclairemd.com

Received: July 09, 2020 | Published: September 21, 2020

However, in this particular article, he only addresses his medical conditions as follows:

Obesity: weight and waistline

Diabetes: daily glucose, postprandial plasma glucose (PPG) \& fasting plasma glucose (FPG)

Hypertension: systolic blood pressure (SBP) \& diastolic blood pressure (DBP)

Hyperlipidemia: high-density lipoprotein cholesterol (HDL) \& low-density lipoprotein cholesterol (LDL), \& triglycerides

Kidney: albumin-to-creatinine ratio (ACR)

Thyroid: thyroid stimulating hormone (TSH)

On $1 / 1 / 2012$, he started to collect his input data for this metabolism model, however, most of the input data had various starting dates after $1 / 1 / 2012$, which can be seen in the attached figures. It is also important to mention that his primary medical conditions between 1998 and 2010 for obesity, diabetes, hypertension, and hyperlipidemia were worse than illustrated in the figures shown. The bad data were not entered into his software database because the system was developed during the period of 2012-2014.

Listed below are his worst conditions from his prior medical examination reports (between 1995 and 2011):

Weight: 220 lbs. (1999)

Glucoses: 280 - $390 \mathrm{mg} / \mathrm{dL}$ (2010)

Blood pressure: 180/110 mm Hg (2010)

Triglycerides: $1,161 \mathrm{mg} / \mathrm{dL}$ (2010)

ACR: 116 mg/g(2010)

\section{Results}

The top diagram of Figure 1 shows his $\mathrm{HbA1C}$ values during a long period of 20.5 years from $1 / 1 / 2000$ to $6 / 25 / 2020$. The Red Cross signs are lab-tested A1C data, while the blue curve is his predicted A1C since 1/1/2012. The middle diagram reflects these two HbA1C 
values since 1/1/2012 (8.5 years). For 12 years, from 2000 to 2011, his lab-tested A1C data were "all over the map" between $5.7 \%$ and $10.0 \%$, with $\sim 80 \%$ of them $>6.5 \%$, which indicates diabetes; however, he was diagnosed with type 2 diabetes (T2D) in 1995. After 1/1/2012, his lab-tested $\mathrm{A} 1 \mathrm{C}$ has been maintained between $6.3 \%$ and $7 \%$. It should be emphasized that since $12 / 8 / 2015$, he has been completely off diabetes medications and the majority of his lab A1C data during this "drug free" period has remained within $6.3 \%$ and $6.7 \%$. The bottom diagram of Figure 1 depicts his daily average glucose, PPG, and FPG values in the period from $1 / 1 / 2012$ to $6 / 25 / 2020$. His glucose levels are within $109 \mathrm{mg} / \mathrm{dL}$ and $146 \mathrm{mg} / \mathrm{dL}$, with an average glucose around $123 \mathrm{mg} / \mathrm{dL}$. Since 12/8/2015, during this drug-free period, his average glucoses have reached below $120 \mathrm{mg} / \mathrm{dL}$ which means he is no longer a T2D patient. However, he knows the truth since he measures his glucoses approximately 240 times per day using an upgraded CGM sensor device. Every time when he did not follow his own stringent rules of diet and exercise, his PPG would increase, occasionally reaching above $200 \mathrm{mg} / \mathrm{dL}$. This proves that the damage to his pancreatic beta cells are permanent and the impacts remain. Therefore, from a biochemical viewpoint, he continues to be a T2D patient even though his mathematically average glucose is remarkable $(<120 \mathrm{mg} / \mathrm{dL})$.

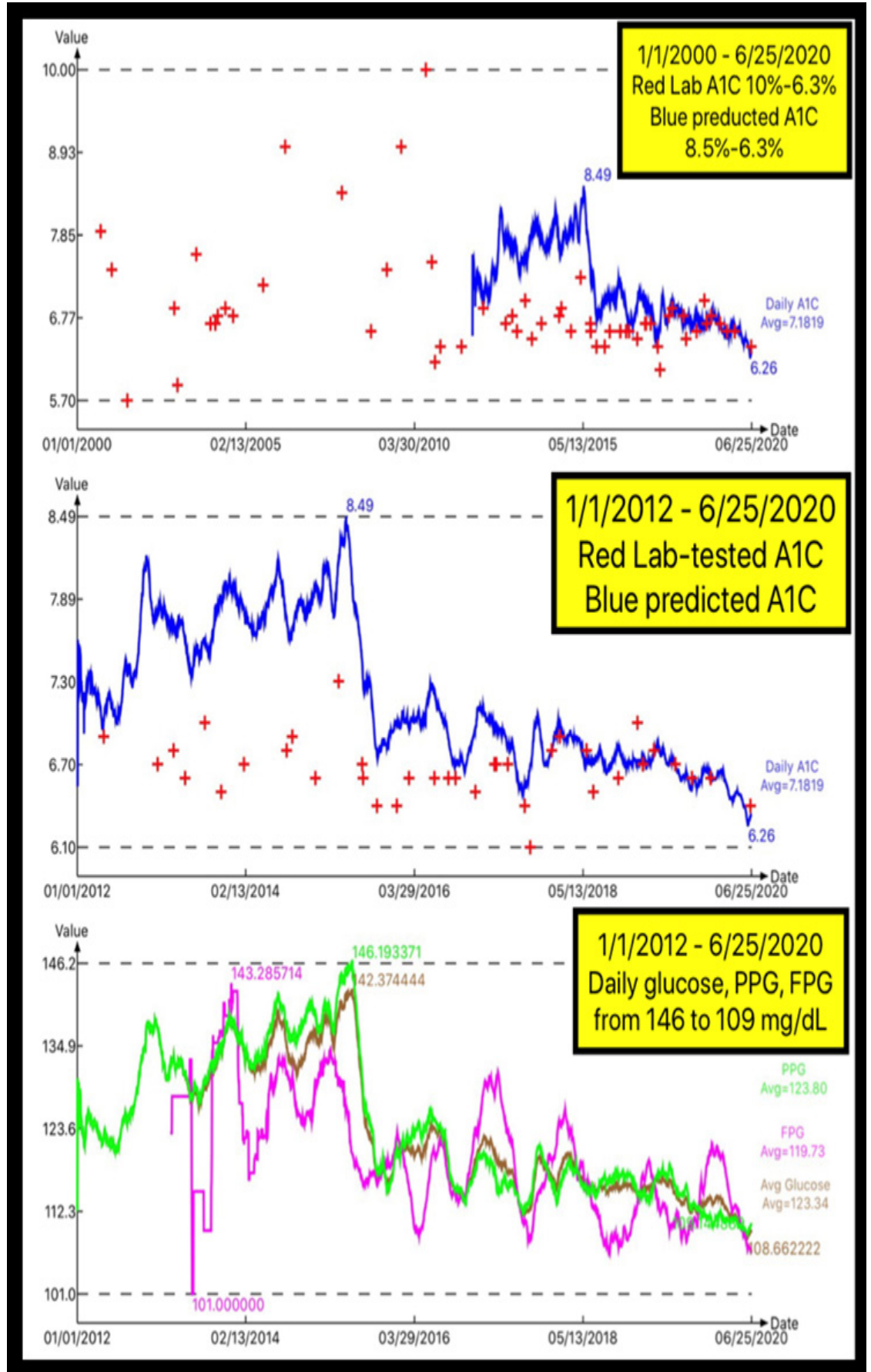

Figure I $\mathrm{HbAIC}$ and Glucoses. 
Figure 2 shows his weight and waistline for the period 1/1/2012 through 6/25/2020. His weight was $145 \mathrm{lbs}$. when he was 20 years old but started to gain weight in 1987. Ten years later, his weight increased to $220 \mathrm{lbs}$. (BMI 33) in 1997, $198 \mathrm{lbs}$. (BMI 29) in 2000, $191 \mathrm{lbs}$. (BMI 28) in 2012, and gradually decreased to $175 \mathrm{lbs}$. (BMI
26) in 2016, and finally to $172 \mathrm{lbs}$. (BMI 25) in 2020. During the same period, his waistline reduced from 44 inches $(112 \mathrm{~cm})$ to 32 inches $(81 \mathrm{~cm})$. In summary, he has turned his obesity situation to a normal condition.

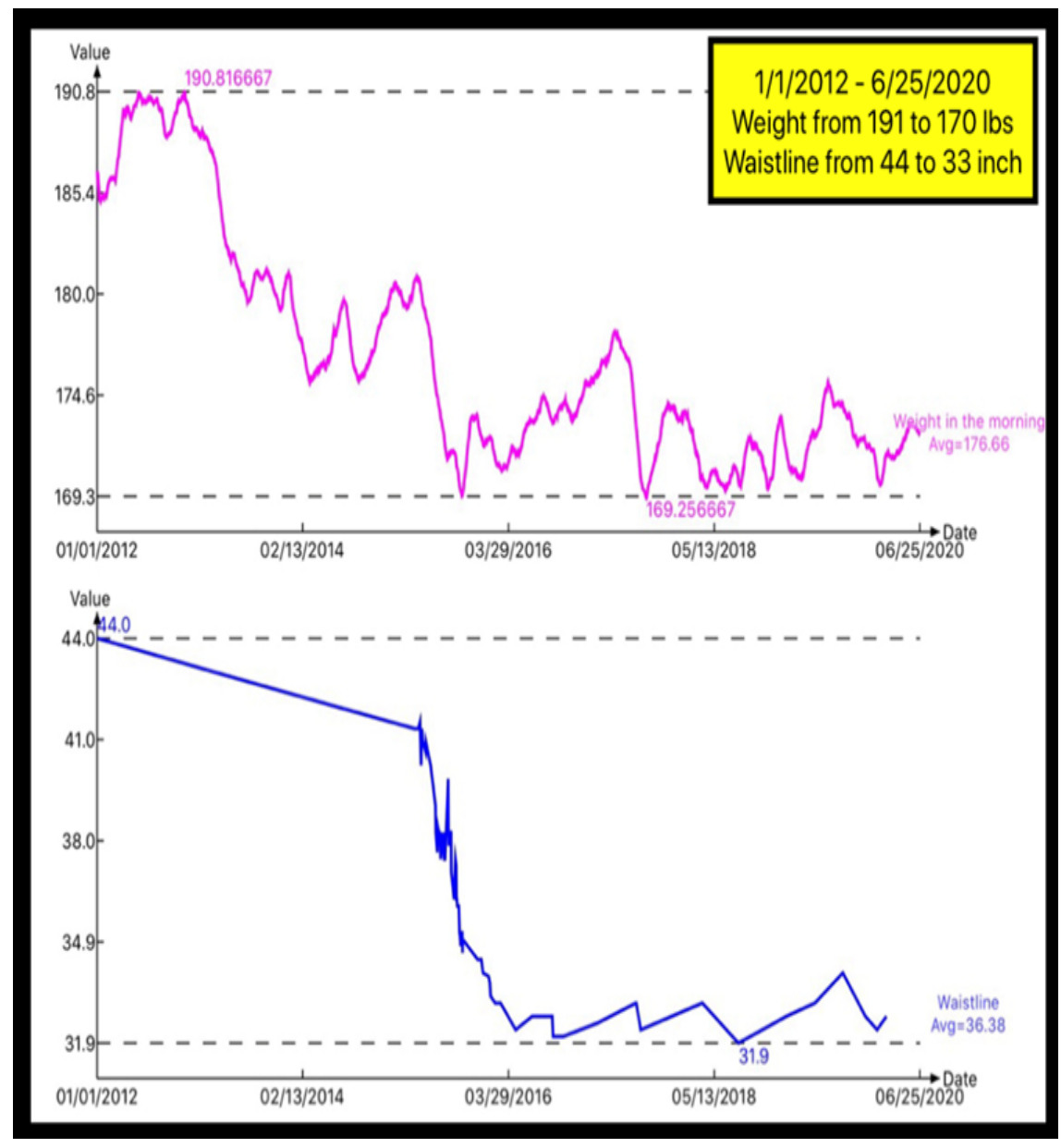

Figure 2 Weight \& waistline.

Figure 3 reflects his blood pressure and lipid conditions. During 1995-2001, his blood pressure reached to $180 / 110$ (hypertension) and his triglycerides reached to 1,161 , which is almost $8 \mathrm{x}$ over the maximum limit of 150). Obviously, this is a dangerous level and he was considered a hyperlipidemia patient as well. He does not remember and cannot locate his old records of HDL and LDL for the period before 2012. Nevertheless, Figure 3 indicates his improvements in both areas. He no longer has hypertension and hyperlipidemia, since he maintains a normal level on both fronts, blood pressure and lipids. His current SBP/DBP has been under 120/80 and his Triglycerides $<150, \mathrm{HDL}>40, \mathrm{LDL}<130$, total cholesterol $<200$.

The top diagram of Figure 4 shows that his MI and GHSU has been brought down from $140 \%$ in 2012 to $54 \%$ in 2020 . Please note that the break-even line is $73.5 \%$, which is healthy if under $73,5 \%$ and unhealthy if above $73.5 \%$. This excellent result of his metabolism is due to his efforts and improvements on his medical conditions and lifestyle management. This also provides a strong indication of his longevity from viewpoints of both biological prospect and mathematical probability. The bottom diagram addresses two other important diabetes-related complications such as kidney and thyroid. ACR is albumin-to-creatinine ratio which measures the protein amount in the urine. The maximum level allowed for ACR is $30 \mathrm{mg} / \mathrm{g}$. His ACR reached $116 \mathrm{mg} / \mathrm{g}$ in 2010, which is almost 4x higher than the maximum level allowed. His ACR was still at $35 \mathrm{mg} / \mathrm{g}$ (above 30 ) in 2013, but he has maintained it below $30 \mathrm{mg} / \mathrm{g}$ from 2014 to 2020 with his recent ACR records of around $10 \mathrm{mg} / \mathrm{g}$. In other words, he has successfully self-repaired his damaged kidney via his diabetes control and stringent lifestyle management. TSH is a thyroid stimulating hormone for measuring its functional level. TSH levels typically fall between 0.4 to $4.0 \mathrm{mU} / \mathrm{L}$. In early 2014, his TSH level was 6.32 and decreased to around 2.0 since 2016. This normal appearance of TSH level could be the result of his taking hyperthyroidism medication (Levothyroxin $75 \mathrm{mg}$ ). However, since 1/19/2020, he has reduced his dosage in half to $37.5 \mathrm{mg}$ per day. Due to COVID-19 quarantine restriction, he cannot go to a medical lab to test his TSH level in order to verify the effect from his medicationreduction. ${ }^{1-4}$ 


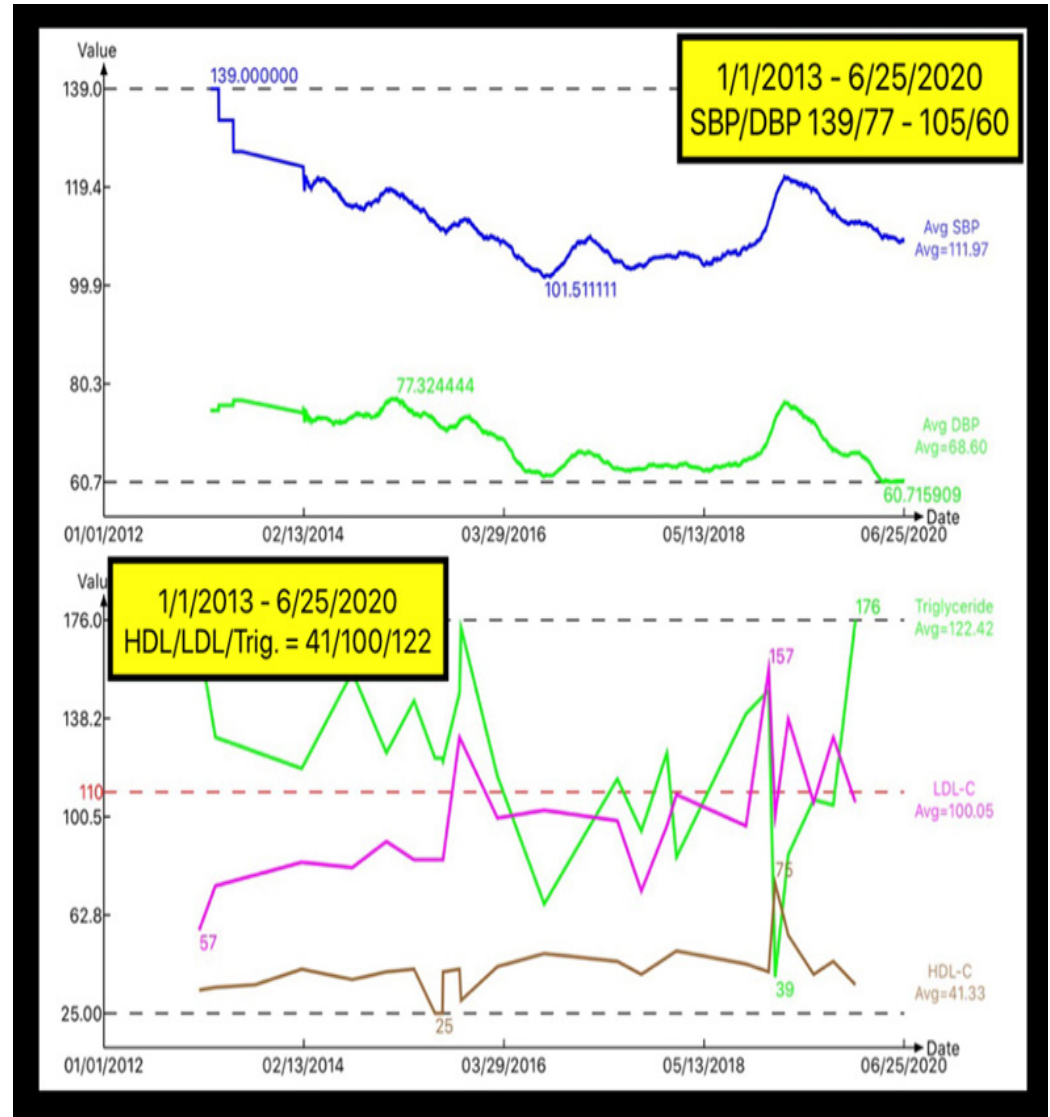

Figure 3 Blood pressure \& lipid.

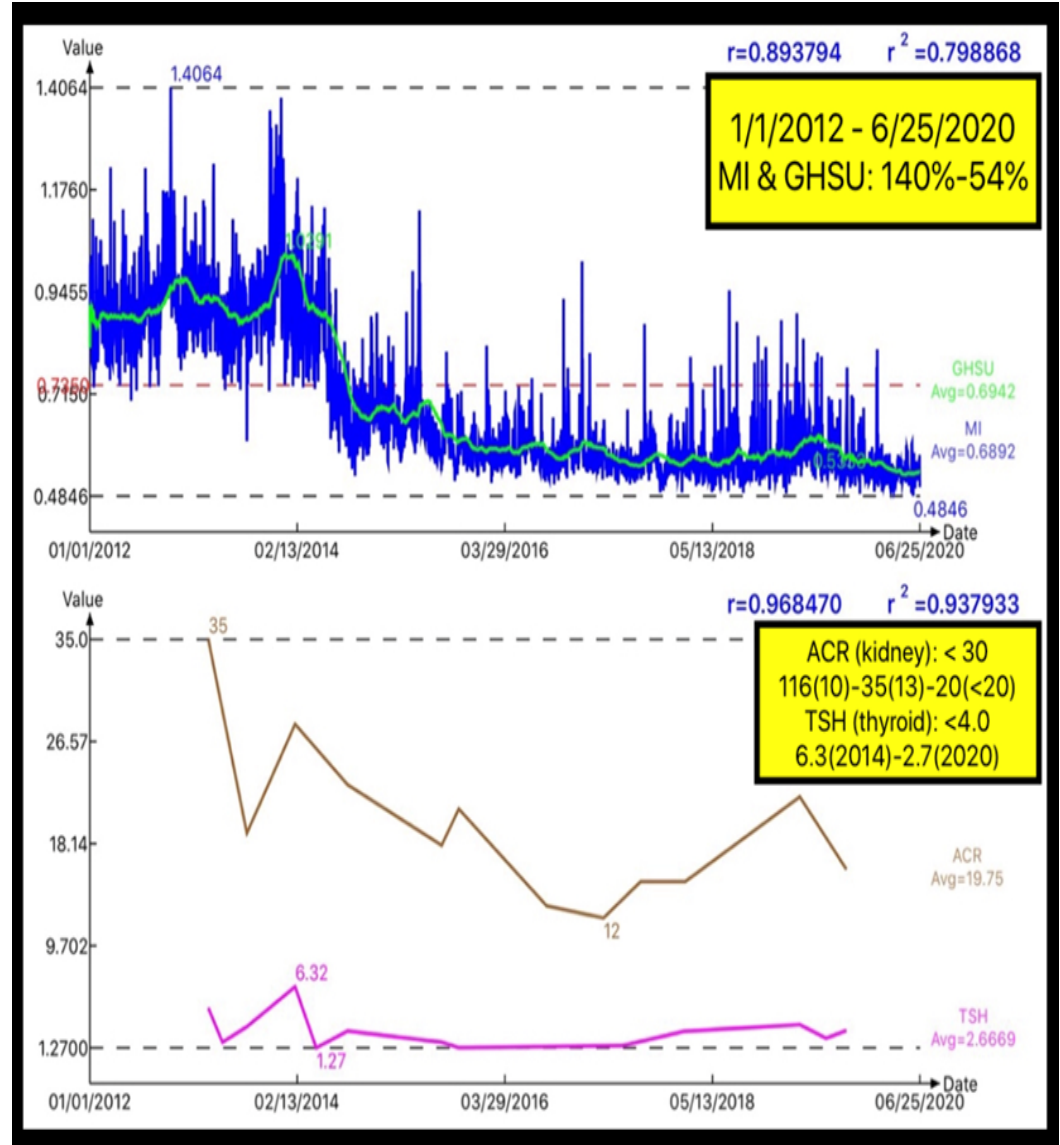

Figure $4 \mathrm{MI}, \mathrm{GHSU}, \mathrm{ACR}$, \&TSH.

Citation: Hsu GC.A geriatric study of longevity via big data analytics of metabolism and medical conditions using GH-Method: math-physical Medicine (No. 284). MOJ Gerontol Ger. 2020;5(5):I50-I55. DOI: I0.I5406/mojgg.2020.05.00248 


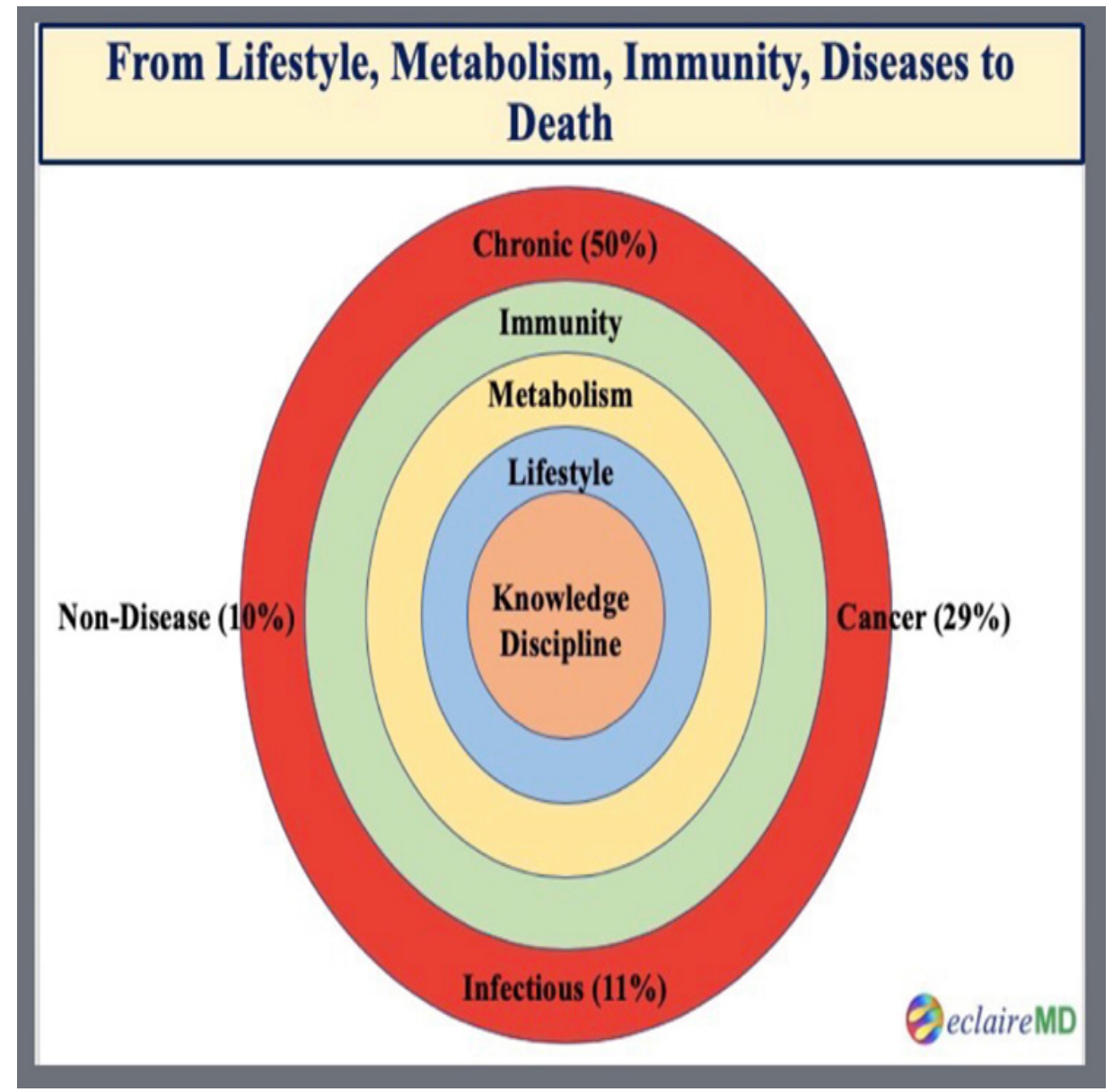

Figure 5 From lifestyle through metabolism, immunity, diseases and death.

\section{Conclusion}

The author has gone through a detailed explanation regarding his primary medical conditions. In summary, he has turned his health conditions from having severe T2D and related complications into a healthy person with his chronic diseases under control.

Medical conditions are only half of the picture of the metabolic effect, where the other half is lifestyle management. This is probably more important than medical conditions since lifestyle is the foundation and "root cause" of the total picture of health. Once More, lifestyle includes six big categories, including food, water, exercise, sleep, stress, and daily routines. It must be treated seriously. Lifestyle is a significant scientific topic, which needs complicated mathematics to decode and reassemble the internal categories into a solid foundation of health and longevity.

This big data analytics is based on $\sim 2$ million data over 8.5 years. His developed metabolism model have shed some light about the impact on his longevity concerns due to his overall metabolism changes, especially including his improvements on all of his known medical conditions. These significant improvements on his chronic diseases and complications have definitely contributed to his perspective of longevity.

His metabolism model is a highly effective tool to investigate the subject of geriatrics and longevity. In figure 5, moving from the inner circle towards the outside rings, it depicts that stringent lifestyle management leading into a good metabolism state, and then converting into a strong immunity to fight against three major disease categories such as chronic diseases and complications (50\% of death), cancers ( $29 \%$ of death), and infectious diseases (11\% of death), except for the remaining $10 \%$ of non-diseases related death cases. This is a logical way to achieve longevity which is also the core of geriatrics research branch. Readers can find more detailed information from References 1 through 4 regarding the author's previous work results in this arena.

\section{Acknowledgments}

First and foremost, the author wishes to express his sincere appreciation to a very important person in his life, Professor Norman Jones at MIT and University of Liverpool. Not only did he give him the opportunity to study for his PhD at MIT, but he also trained him extensively on how to solve difficult problems and conduct any basic scientific research with a big vision, pure heart, and integrity.

The author would also like to thank Professor James Andrews at the University of Iowa. He helped and supported him tremendously when he first came to the United States. He believed in him and prepared him to build his solid engineering and computer science foundation. $\mathrm{He}$ is forever grateful to his mentor, who has a kind heart and guided him during his undergraduate and master's degree work at Iowa. 


\section{Conflicts of interest}

The authors declare have no conflict of interest about the publication of this paper.

\section{References}

1. Hsu Gerald C. Effective health age resulting from metabolic condition changes and lifestyle maintenance program using GH-method: mathphysical medicine (No. 223). eclaireMD Foundation, USA. 2020.
2. Hsu Gerald C. A geriatric study of self-recovering diabetes conditions using GH-Method: Math-physical medicine (No. 280). eclaireMD Foundation, USA. 2020.

3. Hsu Gerald C. Linkage among metabolism, immune system, and various diseases using GH-Method: math-physical medicine (No. 235). eclaireMD Foundation, USA. 2019

4. Hsu Gerald C. Risk probability of having a metabolic disorder induced cancer using GH-Method: Math-physical medicine (No. 263). eclaireMD Foundation, USA. 2019. 